\title{
Problems of increasing animal production
}

\section{By J. C. SHaw, Animal Production and Health Division, FAO, Rome, Italy}

In a recent survey by the United States Department of Agriculture (196I) it was estimated that the animal-protein shortage in the deficit countries, in terms of non-fat milk solids, was the equivalent of $\mathrm{I} \cdot 8$ million metric tons or roughly one-third of the U.S. annual milk production. The most critical shortages were noted to be in the Far East, followed by communist Asia, Africa and Latin America. This survey had been preceded by the 1960 report of FAO, The State of Food and Agriculture, in which it was concluded that per caput supplies of livestock products in the less developed countries had not generally increased during the past few years and indeed had decreased in some instances (FAO, 1960). It was further noted that although an increase in livestock production is the most needed form of diversification in the less developed regions there had been in fact a decrease. It seems obvious that the measures taken to date to improve livestock production in many of the less developed or developing countries have been woefully inadequate.

In addition to its important role of providing high-quality protein, other nutritional essentials and such things as wool and draught power, all of which are much needed by the peoples of the developing countries, improved livestock production is essential to the maintenance and further improvement of crop production through increased soil fertility. Further it should be recognized that much of the earth's surface can be utilized for the production of food for man only by grazing it with livestock. It should also be recognized that it is only through utilization by livestock that crop residues and various by-products and waste products unsuitable for man can be converted into edible human food. Since space does not permit a detailed analysis of all the factors that may affect animal production, I will emphasize principally the more important technological aspects.

\section{Animal nutrition}

In searching for the reason for the failure of animal production to keep pace with the production of food crops in developing countries in recent years, inadequate nutrition has been singled out as the most important single factor. Thus the FAO. Animal Production and Health Meeting, held in Cairo in 1960, was in unanimous agreement with this view and recommended that strong steps be taken to correct the situation. Similarly, the Tenth Session of the FAO Conference placed special emphasis on the need for FAO to improve and expand the work in animal nutrition and management, stressing particularly the need for greater emphasis on the integration of livestock production and grassland production and management (FAO, 1959).

In October I96I sixteen members of the FAO Expert Panel on Animal Nutrition, all of whom are leading animal scientists, representing all regions of the world, met in Washington, D.C., to identify and discuss means of solving the major animal 
nutrition problems of the developing countries. These deliberations contribute the main background for my discussion.

Animal scientists agree that the enhancement of animal production in most developing areas must be based on increased production of grass and forage, or of cereal grains and legumes, or of both, and the proper management of livestock so as best to utilize these feeds. Though fodder materials in the wet tropics are high yielding they have a low dry-matter content which, together with the depressing effect of the tropical environment on appetite, renders it difficult to achieve a sufficient dry-matter intake. The situation is further aggravated by the relatively high fibre content of these forages which increases the heat load under most conditions. With proper management of animals and pastures, including controlled grazing so that the forages may be used at an early stage, the protein content should be adequate. Owing to the seasonal nature of their production greater attention should be given to methods of preserving the forages.

Additional research is much needed on the establishment of new varieties of pasture legumes that can survive in the tropics and subtropics, particularly in the arid areas. There is also a great need for more information on the nutrient requirements of grazing animals, the amount of food eaten by them at pasture and its nutrient content. It is becoming evident that grazing increases the nutrient requirements of an animal, and for this and other reasons feeding standards have only restricted application to animals on pasture.

In the arid tropics, including dry forest areas, steppes, savannahs and scrub forests, water is the limiting factor for plant growth and unless proper stocking and animal management are maintained the land may become a waste. 'The 'standing hay' and browse have usually a high dry-matter and a high crude-fibre content and lignification occurs early. For most of the year the crude-protein content is between 2 and $4 \%$, although that of the browse may sometimes be higher and it is an important source of nutriment for ruminants in many areas of the world. More studies are needed on drought-resistant trees, which would provide suitable forage for ruminants.

The extent to which non-protein nitrogen may be used successfully to supplement low-protein roughages, such as 'standing hay' of low quality, needs further clarification. In some places 'standing hays' are sprayed with mixtures of molasses and urea; little experimental justification for this practice has been published in scientific journals. More information is needed on the basic aspects of nitrogen metabolism in the ruminant in order to predict the effectiveness of non-protein nitrogen supplements under a variety of conditions.

In most parts of the world low-quality roughage constitutes an important source of energy for ruminants; in India dry and green fodders, mostly of a poor quality, supply $95 \%$ of the energy for livestock (Wright, r96I). The processing of cellulosic materials with chemicals, and especially the treating of straws with alkali can produce a feed which is of considerable nutritive value but owing to the large quantities of water required has been impracticable in most cases. However, recent researches in the U.K. and in the U.S. indicate that energy values of feeds may be altered through 
processing or by the use of certain additives which, by controlling microbial activity, control the relative production of organic acids in the rumen. I believe that the potential is sufficiently great to warrant the organization of a special group to deal with the problem with particular reference to the improvement of the feeding value of straws and other poor-quality roughages so important in the Far East and elsewhere (Shaw, r96r).

Where cereal grains are used largely for human consumption their use for animal production must be limited, but as the standard of living improves the demand for a greater variety of products will increase. In other places the climatic conditions are so favourable that the excellent pastures support a milk and meat industry whose by-products can be used to improve pig and poultry production. Here it should not be overlooked that certain foods suitable for human consumption may be fed to animals justifiably, even when needed in the human dietary, when such foods so balance a ration as to enhance greatly the efficacy of utilization of other nutrient substances suitable only for animal consumption.

Formula feeds are important for the development of the pig and poultry industries, particularly the latter. More information should be obtained on the crude-protein and amino acid content of locally available feeds. Knowledge of the requirements of poultry and pigs for amino acids is important in the designing of economical rations to meet these requirements. It is necessary to establish amino acid requirements for maintenance and growth or production. The necessary vitamins should be provided as premixes adapted to the particular area, the class of stock and the kind of production desired. A survey of the need for synthetic vitamins and other suitable supplements in developing countries would be particularly valuable.

There is often very scant information on the nutrient contents of local foodstuffs in developing countries, but much can be done to design rations for poultry and pigs by making use of the values established for similar foodstuffs in more highly developed countries. As more information becomes available the rations can be further improved.

Another aspect of animal nutrition requiring greater attention in the developing countries is the complex problem of mineral deficiencies and imbalances. Though much of the current research involves the trace-mineral elements, deficiencies of the major minerals such as calcium, phosphorus and magnesium continue to limit animal production in many places, and much of the problem arises from failure to apply the knowledge now available. Animal scientists are becoming increasingly aware of the fact that imbalances of mineral elements constitute a major problem and may be fully as common as simple deficiencies. There is a need to devise simpler methods for rapid field analyses in developing countries and for the preparation of a practical handbook or guide dealing with the subject. This project will be initiated by FAO in 1962.

The more highly developed countries can be of great assistance in tackling some of the more complex problems of mineral deficiency in the developing countries. What is believed to be the first large-scale study of mineral deficiencies and imbalances by an international team of experts is now being organized by FAO to 
assist in the investigation of a number of troublesome problems concerning mineral nutrition in Argentina. The success of this project may determine the feasibility of applying such an approach to similar problems in other developing countries. No small part of the programme will be the training of animal scientists within the country who may continue with the investigations into these and other animal nutrition problems after the research team has completed its assignment.

\section{Animal breeding and management}

There is a growing realization in developing countries of the need to improve the quality of livestock. The major problems lie in the tropical, subtropical and aridzone regions which constitute by far the largest areas in these countries. The different lines of approach which might be adopted for a particular area or situation have been discussed in a number of articles and textbooks on animal breeding and will not be commented upon here in detail. For treatises on the most logical approaches to be taken in many of the developing countries reference is made to the following: Phillips (1948, 1958), Mahadevan (1958), Maule (1961). In recent visits to various countries in the Far East, Near East and Latin America, I observed that in almost all countries attempts are being made to improve the animals through breeding and selection both by governments and private industry, usually with too few animals, insufficient understanding of basic and practical aspects of animalbreeding genetics, or too little consideration of feed supplies or potential feed supplies, of management and of disease and parasite control. Although few individual groups of investigators in developing countries are investing heavily in researches on animal breeding, the aggregate is considerable and one might well question whether a group, country or regional approach through establishment of regional breeding centres would not be more effective and economical. Indeed some consideration is being given to such an approach in the Near East where it has been recommended at the ig60 FAO Near East Animal Production and Health Meeting that sheep stations be established in two or more countries on a co-operative basis for the purpose of improving the Awassi sheep.

Such studies must be continuous and planned for long periods of time; most experimentation and development with livestock must of necessity be of a relatively long-term nature, particularly with experiments on animal breeding because of the long intervals between generations. Genetic studies with livestock must be based upon fairly accurate measurement of an animal's production capacity, including such characteristics as milk and milk-fat production, efficiency of feed utilization, efficiency as a work animal, adaptability to environmental stress, quality and yield of wool, relative amount of meat, fat and bone and reproductive efficiency.

In many of the lesser developed areas information is needed on the productivity of the indigenous livestock under the conditions existing but also with respect to improved conditions of feeding and management which are attainable within a reasonable period of time. A certain amount of wise judgement is required, however, since it would often be wasteful of resources and of a country's potential to embark upon lengthy studies of native cattle whose productivity is strongly suspect. Progress 
by selection only within an indigenous breed is invariably slow, and consideration needs to be given to the possibility of using exotic breeds as the pure breed or for crossing, depending upon their suitability to the area under consideration.

It has been noted by Phillips (1958) that the attempts so far made to improve the productivity of the Zebus have not been too successful. Even under the very best system of breeding and selection it is highly doubtful if these cattle will be raised to levels approaching that of the European breeds. Where the environmental conditions require it, and where certain necessary aspects prevail or can be achieved, such as improved nutrition and control of the major diseases, the most rapid improvement can undoubtedly be attained by crossing the European with the Zebu or other indigenous cattle. In some countries where cattle numbers are considerably in excess of available feed supplies, and where for religious or sentimental reasons they cannot be slaughtered, improvement in productivity is extremely difficult since selection on the basis of productivity is literally impossible. However, there is reason to believe that this situation will improve, though slowly, as the masses become better educated and informed. The breeds available for selection and for crossing are numerous and include animals adapted to a wide variety of environmental conditions (Joshi, McLaughlin \& Phillips, I957; Joshi \& Phillips, 1953; Mason \& Maule, 1960). Efforts to combine the Zebu's resistance to high temperatures with the higher productivity of European breeds have been fairly successful. Some of the more recent studies indicate that there is considerable variability in heat resistance even among breeds of European cattle and that it may be possible through breeding and selection based on careful environmental physiology studies to develop lines which will be both relatively high producing and heat resistant. Considerable information has been accumulated on the tolerance of animals to rigorous conditions, and tests have been devised to indicate the relative tolerance of animals to heat (Lee, I953), and to determine the distribution of heat tolerance in various breeds and strains (Lee \& Phillips, I948; also see Lee, 1959, for references to others). Much more information is needed, however, and it is hoped that more of the available facilities will be used, particularly the climatology chambers. However, greater use should be made of presently available information. The review by Bianca \& Blaxter (I96I) is particularly noteworthy as a summary of much of the available information, including optimal environment for maximum production and means of influencing environment and thus production through building design. In a number of places the productivity of sheep and pigs has been improved greatly by the use of exotic breeds as pure breeds or for crossing. It has moreover become an accepted practice to cross local birds with cross-bred cockerels of proven high productivity.

There can be, of course, a stimulus for the breeding of better animals and for better feeding and management only when there is an adequate market for the livestock product. Even this may not be enough in certain parts of Africa where nomadic tribes look upon cattle as an evidence of wealth and are slow to dispose of them. Another problem in such places is that of inducing the nomadic tribes to adopt a settled and permanent system of farming; equally important is the need to educate existing farmers to change from a monocultural to a mixed system of farming. 
The control of disease and parasites requires continual vigilance and, although means of controlling most of the major diseases such as foot-and-mouth disease, rinderpest, and Newcastle disease in chickens are known and for the most part these diseases are now being contained, new epidemics have appeared in the form of African horse sickness in the Near and Middle East and swine fever in Spain and Portugal. The measures taken to control these and other diseases have recently been outlined by Kesteven (196r) and do not need to be further reviewed here.

In many countries in Africa the tsetse fly continues to prevent the successful raising of cattle and other livestock. Methods which give some degree of control are known but for the most part are uneconomic. Tick-borne diseases continue to be troublesome and continue to require protective measures such as dipping.

Parasitic infestations remain a troublesome problem and, although they are known to be highly correlated with undernutrition (Hart, 1955), this aspect is frequently overlooked especially in developing countries. In New Zealand, where the sheep population is extremely dense, the relation between the incidence of parasites and nutrition is so well understood that when treatment becomes necessary management is said to be at fault. This is one of the places where continual co-operation between the veterinarian and the animal nutritionist is particularly important.

\section{Animal husbandry education, research and extension}

Since this subject was dealt with in considerable detail by the FAO Expert Panel on Animal Nutrition which met in 1961 and of which a report is in Press, this section will be primarily a summary of the discussion of the Panel.

The key to the foregoing - that is, the solution to the major problems in animal production in the developing countries - is personnel trained in the animal sciences and opportunities and facilities for effective work of the limited number who are trained. The traditional veterinary training has not provided the practitioner with the necessary background for research and development of animal science. The veterinary programme is of necessity so oriented for the recognition, treatment and prevention of diseases that animal science can be dealt with only cursorily. Similarly, although considerable agronomic training is mandatory for the animal scientist, the broad range of subjects required for adequate training of the agronomist is such that he can also deal only inadequately with animal science. The fundamental training in biochemistry, physiology, physics and advanced biology now required for undergraduate students in animal science is indicative of the shift that is taking place in the training, and even more it emphasizes the orientation which is occurring in the training for research in animal science. The need for basic, and even more especially for applied, research in most of the developing countries is critical. A well-qualified investigator in animal science needs skills in a whole range of techniques many of which are quite new to this and to related disciplines. The question which arises is the extent to which the lesser developed countries should train at this high level. 
An application of knowledge accumulated in more advanced countries is obviously needed in animal breeding and genetics, animal management, and animal nutrition and physiology, and much of this knowledge can no doubt be obtained from studies in the more highly developed countries which are better equipped for such work. However, we are trying to take a short-cut in the developing countries and to do so a special type of well-trained specialist is needed who, while trained in the fundamentals, is nevertheless conversant with the practical problems requiring solution.

It should be recognized that problems in animal production in the developing countries are frequently more complex and difficult than in those more highly developed and thus require able animal scientists to solve them. In addition, one of the pressing needs is for a corps of animal production extension specialists of wide and balanced training and experience operating with the guidance of the more highly trained animal scientists. Local agriculture can be stimulated greatly by progressive farmers putting into practice such advice as they receive from these extension men. Capital would undoubtedly be needed, and banks and other agencies might help them realize that a stimulus to production will ultimately be to their benefit. Problems of land tenure would need to be dealt with, possibly by a parallel group working in close collaboration.

The relationship between the veterinarian, the animal husbandryman and the agronomist requires some re-evaluation in many parts of the world. At the recent meeting of the FAO Expert Panel on Animal Nutrition it was noted that in large areas the primary concern with animal health has led to stagnation with respect to animal nutrition and animal science in general. Thus in a survey report on Africa South of the Sahara prepared by the (U.S.A.) National Research Council (1959) it was concluded that 'livestock management in Africa is now more conspicuous by its absence than by its practice'. Perhaps the simplest solution is to follow the pattern of most of the more highly developed countries and establish separate faculties of animal husbandry in parallel and in co-operation with veterinary and agronomy faculties. This pattern is beginning to develop in some of the Latin American countries. Indeed there is a remarkable upsurge of interest in many of those countries in achieving greater co-ordination, both in the educational and developmental aspects, between animal production and pasture and forage production and management. One of the more promising educational plans in that region consists of 2 years basic university training for all three disciplines followed by 3 years of specialization in either veterinary medicine, animal husbandry or agronomy, with the three faculties co-operating in providing service courses for each other. Such training should be reflected in similar co-operative relationships in research and extension-something which is all too often lacking at the present time. Extension services, although extremely important for the promotion of agricultural production, are of limited value for the augmentation of livestock production unless they include a corps of general practitioners in animal production.

The Panel concluded that there is a need for a few centres in the various regions, similar to those sponsored by the Rockefeller Foundation, where basic research on 
local problems can be investigated and where advanced training can be given, with some of the more promising students being sent abroad for extra training.

The subject of animal husbandry education requires more study on a world-wide basis. In recognition of this it has now been decided to deal with it as one of the major items for discussion at a World Animal Production Conference to be held in Rome in 1963 under the auspices of the various animal production associations of the world in co-operation with FAO.

\title{
REFERENCES
}

Bianca, W. \& Blaxter, K. L. (1961). Int. Congr. Anim. Husb. virr. Hamburg, , , 1 13.

FAO (1959). Report of the Ioth Session of the Conference of the Food and Agriculture Organization. Rome: FAO.

FAO (1960). The State of Food and Agriculture. Rome: FAO.

Hart, G. H. (1955). Breeding Beef Cattle for Unfavorable Environments, p. 40. [A. O. Road, editor.] Austin, Texas: University of Texas Press.

Joshi, N. R., McLaughlin, E. A. \& Phillips, R. W. (1957). F.A.O. agric. Stud. no. 37.

Joshi, N. R. \& Phillips, R. W. (1953). F.A.O. agric. Stud. no. 19.

Kesteven, K. V. L. (196r). Discovery, June i96r, p. 107.

Lee, D. H. K. (1953). F.A.O. Develpm. Pap. no. 38. (Anim. Br. Abstr. 22, 264).

Lee, D. H. K. (1959). Anim. Br. Abstr. 27, I.

Jee, D. H. K. \& Phillips, R. W. (1948). F. Anim. Sci. 7, 39 I.

Mahadevan, P. (1958). Dairy Cattle Breeding in the Tropics. Farnham Royal, Bucks.: Commonwealth Agricultural Bureaux.

Mason, I. L. \& Maule, J. P. (I g6o). The Indigenous Livestock of Eastern and Southern Africa. Farnham Royal, Bucks.: Commonwealth Agricultural Bureaux.

Maule, J. P. (196I). Impact Sci. Soc., Paris, II, 3.

National Research Council (I959). Recommendations for Strengthening Science and Technology in Africa South of the Sahara. Washington, D.C.: National Academy of Sciences-National Research Council.

Phillips, R. W. (1948) Breeding Livestock Adapted to Unfavorable Environments. Rome: FAO.

Phillips, R. W. (1958). Sci. Amer. 201, no. 6, p. 5 I.

Shaw, J. C. (1961). Int. Congr. Anim. Husb. vill. Hamburg, x, 29.

United States Department of Agriculture ( 196 I). The World Food Deficit. Washington, D.C.: Government Printing Office.

Wright, N. C. (196r). IIunger : Can It Be Averted? London: British Association for the Advancement of Science.

\section{Livestock production with particular reference to the nutritional problems of West Africa}

\author{
By T. J. Lansbury*, Walklands Farms Ltd, Bransby, Saxilby, Lincs.
}

\section{Introduction}

Livestock throughout West Africa, by temperate standards, have a low rate of growth and reproduction. This aspect of low productivity is still widely attributed to the inherent characteristics of West African livestock, despite the early work of Anderson (1933) in Northern Nigeria, which indicated clearly the role of malnutrition in bringing about low productivity. Recently Oyenuga (I958) has reviewed the factors affecting productivity and suggested that nutritional factors are at present

*Lately, Faculty of Agriculture, University College of Ghana. 